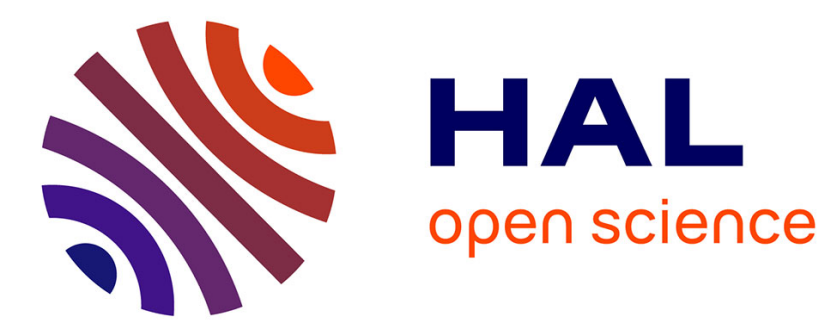

\title{
Radiochemical ageing of poly(ether ether ketone)
}

Emmanuel Richaud, Paulo Ferreira, Ludmila Audouin, Xavier Colin, Jacques

Verdu, Carole Monchy-Leroy

\section{To cite this version:}

Emmanuel Richaud, Paulo Ferreira, Ludmila Audouin, Xavier Colin, Jacques Verdu, et al.. Radiochemical ageing of poly(ether ether ketone). European Polymer Journal, 2010, 46 (4), pp.731-743. 10.1016/j.eurpolymj.2009.12.026 . hal-02269369

\section{HAL Id: hal-02269369 \\ https://hal.science/hal-02269369}

Submitted on 22 Aug 2019

HAL is a multi-disciplinary open access archive for the deposit and dissemination of scientific research documents, whether they are published or not. The documents may come from teaching and research institutions in France or abroad, or from public or private research centers.
L'archive ouverte pluridisciplinaire HAL, est destinée au dépôt et à la diffusion de documents scientifiques de niveau recherche, publiés ou non, émanant des établissements d'enseignement et de recherche français ou étrangers, des laboratoires publics ou privés. 


\title{
Radiochemical ageing of poly(ether ether ketone)
}

\author{
Emmanuel Richaud ${ }^{\mathrm{a}, \mathrm{b}, *}$, Paulo Ferreira ${ }^{\mathrm{a}}$, Ludmila Audouin ${ }^{\mathrm{a}}$, Xavier Colin ${ }^{\mathrm{a}}$, Jacques Verdu ${ }^{\mathrm{a}}$, \\ Carole Monchy-Leroy ${ }^{\mathrm{b}}$
}

${ }^{a}$ Arts et Metiers ParisTech, CNRS, PIMM, 151 bd de l'Hôpital, 75013 Paris, France

${ }^{\mathrm{b}}$ EDF RE'D, MMC, Site des Renardières, 77818 Moret Sur Loing, France

Keywords:

Poly(ether ether ketone)

Radiochemical ageing

Oxidation

Chain scissions

Crosslinking

\begin{abstract}
A B S T R A C T
Thin $(60 \mu \mathrm{m})$ and thick $(250 \mu \mathrm{m})$ samples of poly(ether ether ketone) were subjected to radiochemical ageing at $24 \mathrm{kGy} \mathrm{h}^{-1}$ dose rate for doses up to $30.7 \mathrm{MGy}$ at $60{ }^{\circ} \mathrm{C}$ in air. FTIR spectrophotometry (hydroxyl and carbonyl build-up), ATR microscopy (oxidation profiles), ammonia gaseous treatment (determination of carbonyl nature), density, DSC (glass transition temperature, cold crystallization and melting point changes), and gel content measurements (crosslinking) were conducted for examination of polymer degradation. Thin samples were shown to undergo principally chain scission process whereas thick ones undergo mainly crosslinking. This difference can be attributed to the kinetic control of oxidation by oxygen diffusion. A mechanistic scheme was proposed from radiochemical yields estimations.
\end{abstract}

\section{Introduction}

In the aim to lengthen the nuclear plant lifetime without replacing expensive materials, and guarantee they can safely operate beyond their 40 years license, many researches were conducted on the radiochemical ageing of cable insulation [1] made of rubbers, plasticized PVC or polyethylene, or polymers of high thermomechanical performances such as poly(ether ether ketone) (PEEK). PEEK is a semi-crystalline polymer relatively insensitive to common solvents including water. Its amorphous phase has a glass transition temperature $\left(T_{\mathrm{g}}\right)$ close to $140{ }^{\circ} \mathrm{C}$. A relatively high stability in radiochemical ageing is expected due to its aromatic content. PEEK thermal ageing has been widely studied [1-7] in comparison with radiochemical ageing. Sasuga et al. [8] have studied the effect of irradiation under vacuum. The changes of mechanical properties and glass transition temperature revealed thus the predominance of crosslinking. Irradiation in the presence of oxygen was recently studied [9] at high dose rate i.e. in

\footnotetext{
* Corresponding author. Address: Arts et Metiers ParisTech, CNRS, PIMM, 151 bd de l'Hôpital, 75013 Paris, France.

E-mail address: emmanuel.richaud@paris.ensam.fr (E. Richaud).
}

conditions where oxidation effects are negligible because oxidation is diffusion limited and thus restricted to a very thin superficial layer. Since dose rates are considerably lower in practical applications, oxidation is expected to play a non negligible role. Hence, we were interested in studying radiochemical ageing in conditions favouring oxidation (lower dose rate, lower sample thickness), and appreciating the differences between anaerobic and oxidative ageing as well from chemical (FTIR, derivation treatments) as from physical (DSC, density, sol-gel analysis) measurements.

\section{Experimental}

\subsection{Materials}

PEEK (381G grade - VICTREX ${ }^{\circledR}$ ) was supplied as pellets. These latter were extruded to obtain nearly amorphous $60 \mu \mathrm{m}$ thin films using the following procedure: pellets were first dried $\left(3 \mathrm{~h}, 150{ }^{\circ} \mathrm{C}\right)$ [10] and then processed in a twin screws Brabender extruder $\left(T_{\text {zone } 1}=350{ }^{\circ} \mathrm{C}\right.$, $T_{\text {zone } 2}=380{ }^{\circ} \mathrm{C}, T_{\text {zone } 3}=390{ }^{\circ} \mathrm{C}$ at $10 \mathrm{rev} \mathrm{min}^{-1}$, and torque between 72 and $75 \mathrm{Nm}$ ). Extruded films were directly 
quenched in water so that to obtain quasi-amorphous samples.

PEEK was also supplied as $250 \mu \mathrm{m}$ thick sheaths with an internal diameter close to $1000 \mu \mathrm{m}$ wrapping a copper conductor. Their initial density about 1.290 corresponds to an initial crystallinity ratio close to $23 \%$. Sheaths were irradiated with the $\mathrm{Cu}$ conductor. It means that only one surface was in contact with air versus two for films.

\subsection{Characterization}

\subsubsection{FTIR spectrophotometry}

2.2.1.1. Transmission. FTIR spectra were recorded in transmission mode on an IFS 28 apparatus (Brucker). Free standing films spectra were obtained by the averaging of 32 scans at a $4 \mathrm{~cm}^{-1}$ resolution.

2.2.2.1. Attenuated Total Reflexion microscopy. Thickness of oxidized layer was estimated by Micro-ATR Spectroscopy using a Spotlight 300 apparatus coupled with Spectrum 100 FTIR spectrophotometer (Perkin-Elmer) driven by Spectrum Image software. Sheaths were embedded in a commercial epoxy-amine resin. After curing, samples were polished with 800 and 2400 granulometry disks with a cold water flow. The sample-resin interface was located using PEEK absorptions at 1485 and $926 \mathrm{~cm}^{-1}$. The spectra were recorded at a $16 \mathrm{~cm}^{-1}$ minimal resolution with $1.56 \mu \mathrm{m}$ pixel size.

\subsubsection{Gaseous ammonia treatment}

$\mathrm{NH}_{3}$ derivatization was used to precise the nature of oxidation products. Ammonia was generated from an equimolar solution of $\mathrm{NH}_{4} \mathrm{Cl}(13.4 \mathrm{~g})$ and $\mathrm{NaOH}(10 \mathrm{~g})$ in $100 \mathrm{ml}$ of water. $24 \mathrm{~h}$ treatments were performed in a closed vessel at room temperature before FTIR analysis.

\subsubsection{Density measurements}

Density was measured at $22^{\circ} \mathrm{C}$ using a Mohr balance (Mettler Toledo). Samples ranging from 20 to $50 \mathrm{mg}$ were successively weighted in $\operatorname{air}\left(m_{1}\right)$ and in acetone $\left(m_{2}\right)$ (supplied by VWR, density $\rho_{\text {Acetone }}=790 \mathrm{~kg} \mathrm{~m}^{-3}$ ). PEEK density ( $\rho_{\text {PEEK }}$ ) was thus assessed from

$\rho_{\text {PEEK }}=\rho_{\text {Acetone }} \cdot \frac{m_{1}}{m_{1}-m_{2}}$

Crystallinity ratio was then obtained using

$x_{\mathrm{C}}=\frac{\rho_{\mathrm{C}}}{\rho} \cdot \frac{\rho-\rho_{\mathrm{A}}}{\rho_{\mathrm{C}}-\rho_{\mathrm{A}}}$

with $\rho_{\mathrm{A}}=1.260$ and $\rho_{\mathrm{C}}=1.400$ [11].

\subsubsection{Differential Scanning Calorimetry}

DSC experiments were carried out on a TA Instrument Q1000 apparatus driven by Q Series Explorer software. DSC was previously calibrated with Indium standard. Approximatively $10 \mathrm{mg}$ of sample in a closed aluminium pan was subjected to a $10 \mathrm{~K} \mathrm{~min}^{-1}$ ramp from 50 to $400{ }^{\circ} \mathrm{C}$ (or from 400 to $50^{\circ} \mathrm{C}$ ) under nitrogen purge with a $50 \mathrm{ml} \mathrm{min}{ }^{-1}$ flow rate.

\subsubsection{Sol-gel analysis}

Gel content was estimated by immersing samples in hot trichloroacetic acid (purity $\geqslant 99.0 \%$, titration grade supplied by Sigma Aldrich, melting point c.a. $60^{\circ} \mathrm{C}$ ) at $70^{\circ} \mathrm{C}$ in closed vessel. About $15 \mathrm{~g}$ of acid were used to swell polymer ( $\mathrm{m}_{0}$ mass c.a. $20 \mathrm{mg}$ ). After $24 \mathrm{~h}$, solution was filtered and sample was cautiously washed with distilled water. Insoluble fraction mass $\left(m_{\mathrm{I}}\right)$ was weighted after drying under vacuum $\left(80^{\circ} \mathrm{C}-24 \mathrm{~h}\right)$. The gel fraction $w_{\mathrm{I}}$ was thus

$w_{\mathrm{I}}=m_{\mathrm{I}} / m_{0}$

\subsection{Irradiation}

Irradiations were performed using a ${ }^{60} \mathrm{Co} \gamma$-rays source at $60{ }^{\circ} \mathrm{C}$ under 1.5 bar air pressure ("Brigitte" device, SCK CEN, Mol, Belgium) at $24 \mathrm{kGy} \mathrm{h}^{-1}$ dose rate. Statistical chain scission concentration in a Red Perspex sample (PMMA) allows the total emitted dose to be measured with accuracy better than $5 \%$.

\section{Results}

\subsection{Thin samples}

\subsubsection{FTIR spectrophotometry}

IR spectra of virgin and irradiated samples are shown in Fig. 1. The main changes are:

- a wide band in the $3000-3500 \mathrm{~cm}^{-1}$ range with a double maxima at 3320 and $3260 \mathrm{~cm}^{-1}$ ascribed to hydrogen bonded (possibly phenolic) hydroxyl groups (denoted $\mathrm{POH}$ in the following),

- a sharper one in the $1600-1800 \mathrm{~cm}^{-1}$ range with a maxima at $1725 \mathrm{~cm}^{-1}$ attributed to various types of carbonyl groups (denoted by $\mathrm{PC}=\mathrm{O}$ in the following).

To improve clarity, the spectrum of virgin sample was subtracted to spectra of degraded ones and zooms of respectively hydroxyl and carbonyl regions are presented in Figs. 2a and 3a. Broad hydroxyl band displays a maximum at about $3320 \mathrm{~cm}^{-1}$ indicating that $\mathrm{OH}$ groups are strongly linked to oxygen atoms and aromatic structures

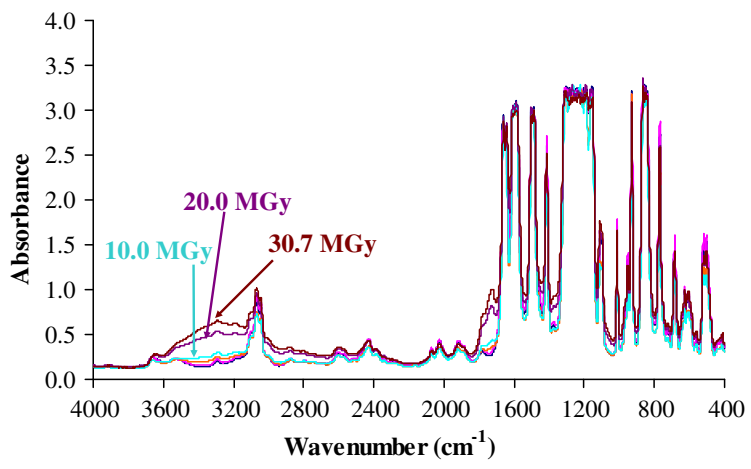

Fig. 1. Full range FTIR spectra of $60 \mu \mathrm{m}$ amorphous PEEK films at different irradiation doses (up to 30.7 MGy). 

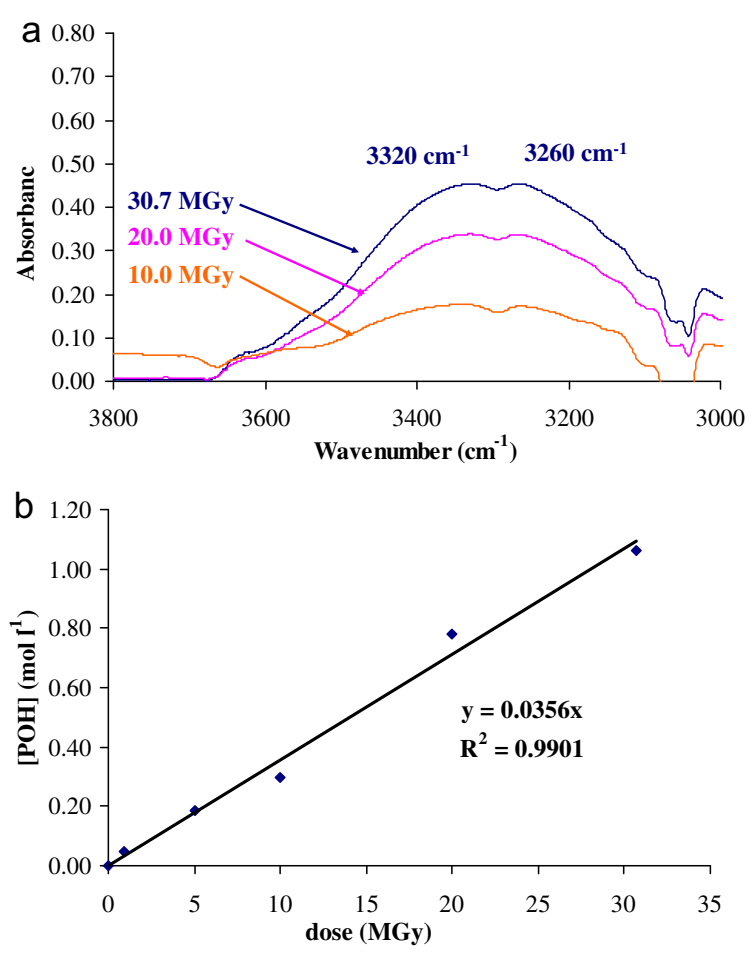

Fig. 2. Subtraction IR spectra changes in the hydroxyl region (a) and kinetic curve of hydroxyl build-up from $3320 \mathrm{~cm}^{-1}$ signal growing-up (b).
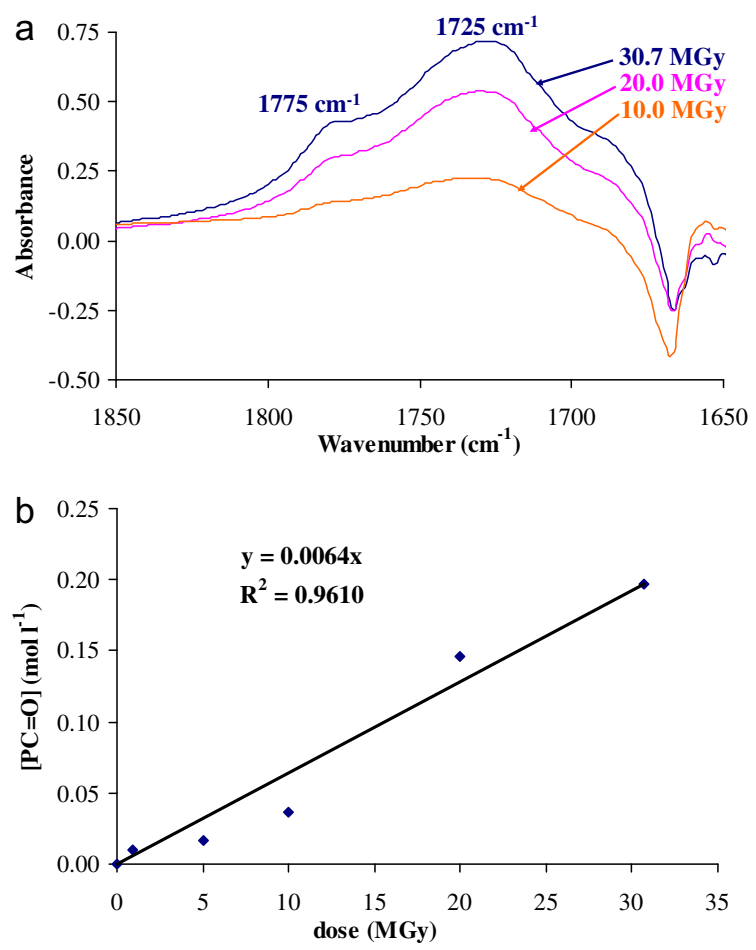

Fig. 3. Subtraction IR spectra changes in the carbonyl region (a) and kinetic curve of carbonyl build-up from $1725 \mathrm{~cm}^{-1}$ signal growing-up (b). by hydrogen bonds. The negative peak in the 3000$3050 \mathrm{~cm}^{-1}$ indicates a partial consumption of aromatic $\mathrm{C}-\mathrm{H}$ groups.

A negative peak at $1660 \mathrm{~cm}^{-1}$ corresponding to the conversion of initial benzophenone unit into other species [12] is observed. Three carbonyl species absorbing at 1690 , 1725 and $1775 \mathrm{~cm}^{-1}$ appear with a clear predominance of $1725 \mathrm{~cm}^{-1}$ product.

A gaseous ammonia treatment induced an increase of the band intensity in the 3200-3400 region (Fig. 4a) and an absorbance decrease in the carbonyl region (Fig. 4b). As previously established, $\mathrm{NH}_{3}$ converts carboxylic acids into carboxylate salts (not observable here because the resulting signal overlaps with virgin PEEK absorptions) and esters to give amides $[13,14]$. The observed changes correspond well to the conversion of initially present aromatic esters (absorbing at $1725 \mathrm{~cm}^{-1}$ ) into amides (stretching $\mathrm{N}-\mathrm{H}$ vibrations at $3300 \mathrm{~cm}^{-1}$ ).

The growth of hydroxyl groups (at $3320 \mathrm{~cm}^{-1}$ ) and carbonyl ones (making the assumption that these latter are essentially esters) was quantified using Beer-Lambert law:

$[\mathrm{PC}=\mathrm{O}]=\frac{\mathrm{DO}_{1725}}{\text { e. } \varepsilon_{1725}}$

$[\mathrm{POH}]=\frac{\mathrm{DO}_{3320}}{e . \varepsilon_{3320}}$

where

$-e$ is the sample thickness $(\mathrm{cm})$.
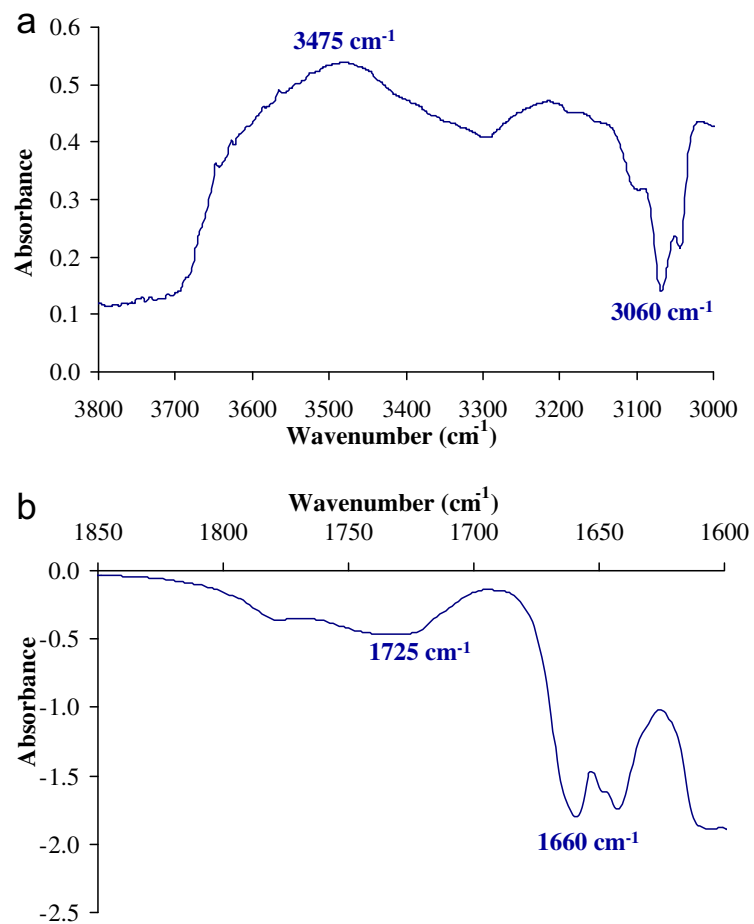

Fig. 4. Effect of $\mathrm{NH}_{3}$ treatment on the IR spectrum of $30.7 \mathrm{MGy}$ irradiated sample (subtracted spectra between treated and untreated sample) in the hydroxyl region (a) and in the carbonyl region (b). 
- $\varepsilon_{3320}$ and $\varepsilon_{1725}$ are the molar absorptivities equal to $701 \mathrm{~mol}^{-1} \mathrm{~cm}^{-1}$ [15] for hydroxyl groups and $600 \mathrm{l} \mathrm{mol}^{-1} \mathrm{~cm}^{-1}$ for carbonyl ones [16-18].

The corresponding kinetic plots (Fig. 2b for hydroxyls, Fig. 3b for carbonyls) are almost linear. The slope for hydroxyl groups is

$\frac{d[\mathrm{POH}]}{d \delta}=3.6 \times 10^{-8} \mathrm{~mol} \mathrm{l}^{-1} \mathrm{~Gy}^{-1}$

and $\frac{\mathrm{d}[\mathrm{POH}]}{\mathrm{d} t}=10^{-7} \times G(\mathrm{POH}) \times I$

- $\delta$ being the dose $(\mathrm{Gy})$

- $I$ being the dose rate $\left(\mathrm{Gy} \mathrm{s} \mathrm{s}^{-1}\right)$

- $G$ being the yield of formation (groups/100 eV)

Since $\delta=I \times \mathrm{d} t$

The radiochemical yield for $\mathrm{POH}$ formation is

$G(\mathrm{POH})=10^{7} \times \frac{\mathrm{d}[\mathrm{POH}]}{\mathrm{d} \delta}=0.36$ groups per $100 \mathrm{eV}$

After a 30.7 MGy irradiation, the hydroxyl concentration is close to $1.1 \mathrm{~mol} \mathrm{l}^{-1}$, i.e. $0.87 \mathrm{~mol} \mathrm{~kg}^{-1}$ what corresponds nearly to one hydroxyl group every four monomer units.

The esters grow-up almost linearly with dose:

$\frac{\mathrm{d}[\mathrm{PC}=\mathrm{O}]}{\mathrm{d} \delta}=0.64 \times 10^{-8} \mathrm{~mol} \mathrm{l}^{-1} \mathrm{~Gy}^{-1}$

which gives

$$
\begin{aligned}
G(\mathrm{PC} & =0)=10^{7} \times \frac{\mathrm{d}[\mathrm{PC}=\mathrm{O}]}{\mathrm{d} \delta} \\
& =0.06 \text { groups per } 100 \mathrm{eV}
\end{aligned}
$$

Carbonyl formation would be thus a relatively rare event compared to hydroxyl formation.

\subsubsection{Differential Scanning Calorimetry}

DSC thermograms of irradiated amorphous films are shown in Fig. 5. Three characteristic transitions are observable:

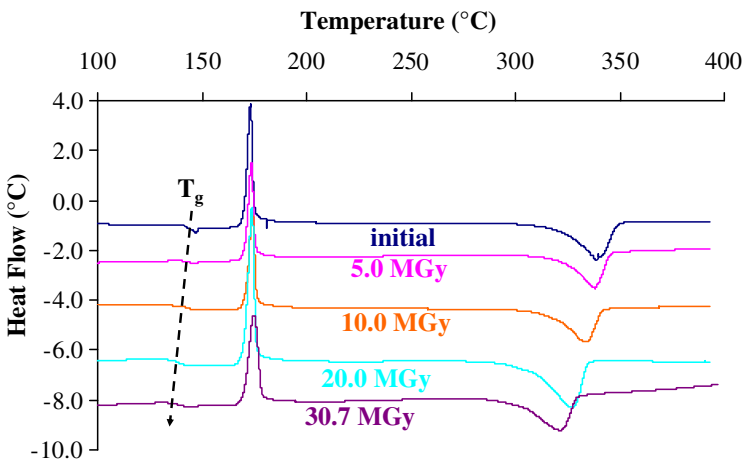

Fig. 5. DSC thermograms of $60 \mu \mathrm{m}$ thick amorphous films for different exposure doses.
- The glass transition temperature at about $140{ }^{\circ} \mathrm{C}$.

- The cold crystallization at about $170{ }^{\circ} \mathrm{C}$.

- The melting point at about $340{ }^{\circ} \mathrm{C}$.

3.1.2.1. Glass transition temperature. $T_{\mathrm{g}}$ decreases almost linearly with irradiation dose (Fig. 6). A linear regression gave

$T_{\mathrm{g}}=144.75-2.3 \times 10^{-7} \times \delta$

$\delta$ being in $\mathrm{Gy}$, and $T_{\mathrm{g}}$ in ${ }^{\circ} \mathrm{C}$.

$T_{\mathrm{g}}$ dependance with molar mass is given by the Fox-Flory equation [19]:

$T_{\mathrm{g}}=T_{\mathrm{g} \infty}-\frac{k_{\mathrm{FF}}}{\bar{M}_{\mathrm{N}}}$

$k_{\mathrm{FF}}$ being the Fox-Flory constant $\left(\mathrm{K} \mathrm{mol} \mathrm{kg}^{-1}\right)$.

According to Saito [20], the reciprocal average number molar mass varies with both chain scission $(s)$ and crosslinking $(x)$ concentration:

$\frac{1}{\bar{M}_{\mathrm{N}}}-\frac{1}{\bar{M}_{\mathrm{N} 0}}=s-x$

By neglecting the existence of crosslinking event in a first approach (which can be partially justified by the absence of gel content for irradiated films as mentioned below), we have thus

$T_{\mathrm{g} 0}-T_{\mathrm{g}}=k_{\mathrm{FF}} \cdot\left(\frac{1}{\bar{M}_{\mathrm{N}}}-\frac{1}{\bar{M}_{\mathrm{N} 0}}\right)=k_{\mathrm{FF}} \cdot s$

Thus $\frac{\mathrm{d} T_{\mathrm{g}}}{\mathrm{d} s}=-k_{F F}$

Since $\frac{\mathrm{d} T_{\mathrm{g}}}{\mathrm{d} s}=\frac{\frac{\mathrm{d} T_{\mathrm{g}}}{\mathrm{d} \delta}}{\frac{\mathrm{d} s}{\mathrm{~d} \delta}}$

and $s=10^{-7} G(s)$

Then $G(s)=-\frac{10^{7}}{k_{\mathrm{FF}}} \cdot \frac{\mathrm{d} T_{\mathrm{g}}}{\mathrm{d} \delta}$

Any PEEK $k_{\mathrm{FF}}$ value was reported in literature to our knowledge. Assuming that $k_{\mathrm{FF}}$ is proportional to $T_{\mathrm{g} \infty}, T_{\mathrm{g}_{\infty}}^{2}, T_{\mathrm{g}_{\infty}}^{3}$ (see 'Appendix'), converging values ranging between 169

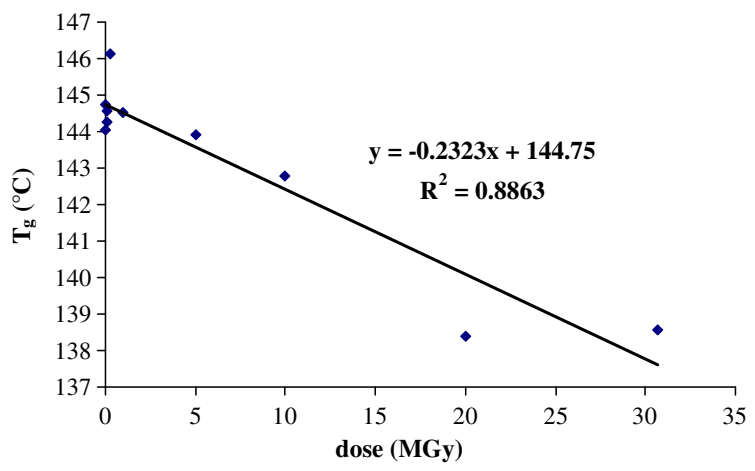

Fig. 6. Decrease of glass transition temperature with irradiation dose for $60 \mu \mathrm{m}$ thick amorphous films 
and $201 \mathrm{~K} \mathrm{~kg} \mathrm{~mol}^{-1}$ were calculated. Taking $185 \mathrm{~K}$ $\mathrm{kg} \mathrm{mol}{ }^{-1}$, one obtains:

$G(s)=0.012$

3.1.2.2. Cold crystallization characteristics. The cold crystallization temperature $T_{\mathrm{CF}}$ and the corresponding enthalpy $\Delta H_{\mathrm{CF}}$ increase with irradiation dose (Fig. 7). $T_{\mathrm{CF}}$ increases slowly from $173{ }^{\circ} \mathrm{C}$ to about $174.5^{\circ} \mathrm{C}$ at $30.7 \mathrm{MGy} . \Delta H_{\mathrm{CF}}$ increases markedly from nearly $20 \mathrm{~J} \mathrm{~g}^{-1}$ for the virgin film to about $34 \mathrm{~J} \mathrm{~g}^{-1}$ for $30.7 \mathrm{MGy}$ irradiated one. This is not surprising because the polymer undergoes chain scission facilitating the polymer crystallization [21].

3.1.2.3. Melting characteristics. Melting enthalpy undergoes small non-monotonic changes. In contrast, the melting point decreases almost linearly with dose rate (Fig. 8). The slope of straightline in Fig. 8 is

$\frac{\mathrm{d} T_{\mathrm{M}}}{\mathrm{d} \delta}=-6.1 \times 10^{-7} \mathrm{KGy}^{-1}$

$T_{\mathrm{M}}$ decrease can be attributed to the limiting effect on crystalline lamellae thickness $l_{C}$ of radiation induced structural modifications. According to Gibbs-Thompson equation:

$l_{\mathrm{C}}=\frac{2 \sigma}{\rho_{\mathrm{C}} \cdot \Delta \mathrm{H}_{\mathrm{M} \infty}} \cdot\left(1-\frac{T_{\mathrm{M}}}{T_{\mathrm{M} \infty}}\right)^{-1}$

where

- $\sigma$ is the surface energy between crystalline and amorphous phase $\left(\mathrm{J} \mathrm{m}^{-2}\right)$,

- $T_{\mathrm{F} \infty}$ and $\Delta H_{\mathrm{F} \infty}$ are respectively the melting temperature and the melting enthalpy of an infinite crystal,

- $\rho_{\mathrm{C}}$ is the crystalline phase density.

Supposing that $T_{\mathrm{F} \infty}, \Delta H_{\mathrm{F} \infty}, \rho_{\mathrm{C}}$, and $\sigma$ changes are negligible during ageing, it gives

$\frac{l_{\mathrm{C} 0}}{l_{\mathrm{C}}}=\frac{T_{\mathrm{M} \infty}-T_{\mathrm{M}}}{T_{\mathrm{M} \infty}-T_{\mathrm{M} 0}}$

i.e. $\frac{l_{\mathrm{C} 0}}{l_{\mathrm{C}}}=1+\frac{T_{\mathrm{M} 0}-T_{\mathrm{M}}}{T_{\mathrm{M} \infty}-T_{\mathrm{M} 0}}$

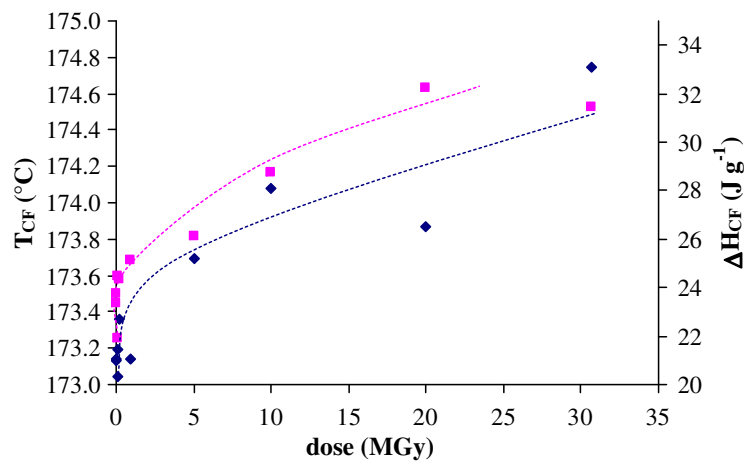

Fig. 7. Cold crystallization temperature $T_{\mathrm{CF}}(\bullet)$ and enthalpy $\Delta H_{\mathrm{CF}}$ against irradiation dose (ם).

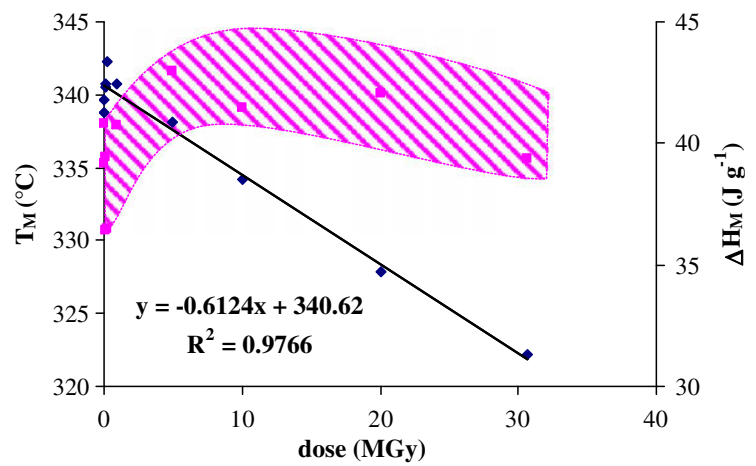

Fig. 8. Melting point temperature $(\bullet)$ and melting enthalpy against irradiation dose for quenched $60 \mu \mathrm{m}$ thick films.

i.e. $\frac{l_{\mathrm{C} 0}}{l_{\mathrm{C}}}=1+\frac{0.61 \times 10^{-6}}{T_{\mathrm{M} \infty}-T_{\mathrm{M} 0}} \cdot \delta$

$\delta$ being expressed here in MGy.

Literature data [22-24] give: $T_{\mathrm{M} \infty}=663 \pm 5 \mathrm{~K}$.

Thus $\frac{l_{\mathrm{C} 0}}{l_{\mathrm{C}}}=1+1.2 \times 10^{-8} \times \delta$

i.e. $l_{\mathrm{C}}=l_{\mathrm{C} 0} \cdot\left(1-1.2 \times 10^{-8} \times \delta\right)$

A 30.7 MGy irradiation would induce a 35\% decrease of lamellae thickness:

$l_{\mathrm{C}}=l_{\mathrm{C} 0} \cdot\left(1-1.2 \times 10^{-8} \times 30.7 \times 10^{6}\right) \sim 0.65 . l_{\mathrm{C} 0}$

It means that the positive effect of chain scission on crystallinity [25] is compensated and even dominated by the negative effect of irradiation induced structural irregularities working as comonomers limiting the lamella growth.

\subsubsection{Gel content measurements}

Thin films $(60 \mu \mathrm{m})$ remained soluble in hot trichloroacetic acid even at high irradiation dose. It suggests that chain scission is dominating which was already observed for many polymers when ageing is not controlled by oxygen diffusion (see 'Section 4'). These results are confirmed by rheometry experiments (not presented here): the Newtonian viscosity decreases as soon as the beginning of exposure.

\subsection{Thick samples}

\subsubsection{FTIR analysis by Attenuated Total Reflection microscopy}

The cross-section of the epoxy embedded irradiated sheaths was analysed by FTIR in ATR mode. Absorbance at $3320 \mathrm{~cm}^{-1}$ changes with depth gave the profile of Fig. 9. Two interesting observations can be made:

1. The hydroxyl concentration profile displays a horizontal plateau in the superficial layer.

2. The thickness of oxidation layer assessed from the $\mathrm{POH}$ depth profile is on the order of $50-100 \mu \mathrm{m}$, depending on the chosen criterion. 


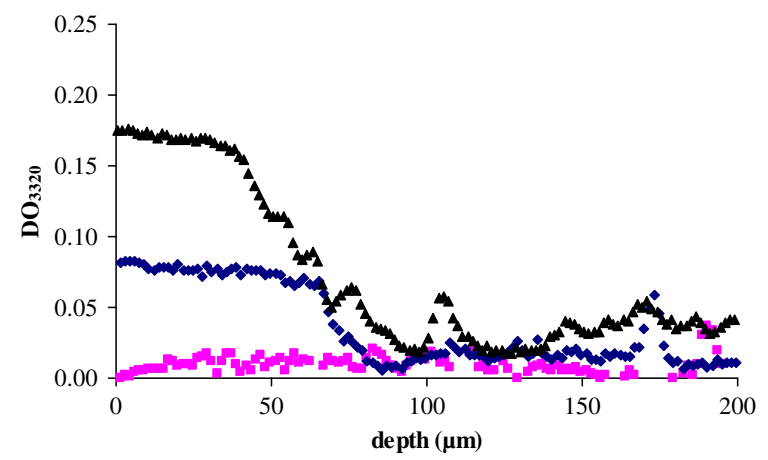

Fig. 9. Changes of oxidized layer profile for irradiated sheaths: 10 MGy, $: 20$ MGy, «: 30.7 MGy.

\subsubsection{Density measurements}

Density measurements were monitored on irradiated sheaths. An increase from 1.290 for virgin sample to 1.297 for 30.7 MGy irradiated one was measured.

Since density decrease can be attributed to destruction of crystals under irradiation [26,27], our results confirm the stability of PEEK crystals under the employed dose rate. Polymers being exposed in their glassy state, chains in amorphous phase cannot integer the crystalline one because of restricted mobility. The observed density increase cannot be caused by chemicrystallization but rather from oxidation since "heavy" oxygen atoms are grafted. Let us denote by $M_{\mathrm{A}}$ the average atomic mass:

$M_{\mathrm{A}}=m_{\mathrm{U}} / N$

where

- $m_{\mathrm{U}}$ is the molar mass of the representative structural unit (RSU).

- $N$ is the number of atoms of RSU.

For non irradiated PEEK, one has

$$
\begin{aligned}
& m_{\mathrm{U} 0}=288 \mathrm{~g} \mathrm{~mol}^{-1} \\
& N_{0}=34 \\
& M_{\mathrm{A} 0}=8.47 \mathrm{~g} \mathrm{~mol}^{-1}
\end{aligned}
$$

The $100 \%$ conversion of aromatic rings into phenolic byproducts would give

$$
\begin{aligned}
& m_{\mathrm{U}}=304 \mathrm{~g} \mathrm{~mol}^{-1} \\
& N_{0}=35 \\
& M_{\mathrm{A} 0}=8.69 \mathrm{~g} \mathrm{~mol}^{-1}
\end{aligned}
$$

Assuming that $\frac{\rho_{0}}{M_{\mathrm{A} 0}}=\frac{\rho}{M_{\mathrm{A}}}$

the total oxidation of amorphous phase would provoke a density increase from 1.260 to 1.293 . For a sheath having a constant crystallinity ratio close to $25 \%$, the density theoretically increases from 1.290 to 1.317 . The lower observed value (1.297) suggests that the degradation is confined in a superficial layer of which depth might be approximated by $l=\frac{0.007}{0.027} \times 250 \sim 60-70 \mu \mathrm{m}$

in good agreement with the above micro-ATR results.

\subsubsection{Differential Scanning Calorimetry}

Thermograms of $250 \mu \mathrm{m}$ thick samples are shown in Fig. 10. In these extruded samples, the initial crystallinity ratio is close to its maximum ( $\sim 25 \%)$ what explains the quasi-absence of cold crystallization exotherm and the weakness of heat capacity change at $T_{\mathrm{g}}$. $T_{\mathrm{g}}$ values were therefore hardly measurable. Even if a small increase was observed, data scattering prevents from a reliable theoretical exploitation.

The melting peak is displaced slightly towards low temperatures and tends to split into two components. However, the melting enthalpy remained almost constant.

We were interested in studying crystallization from the melt during cooling from 400 to $50{ }^{\circ} \mathrm{C}$ at $10^{\circ} \mathrm{C} \mathrm{min}{ }^{-1}$ ramp. Comparison of $30.7 \mathrm{MGy}$ irradiated sample with virgin sample (Fig. 11) calls for the following comments:

1. In irradiated samples, the first heating melting endotherm tends to split into two components. An explanation is proposed in the 'Section 4' part. Nevertheless, the melting enthalpy remained nearly constant, which suggests that PEEK crystals are quite stable under the considered dose rate, in agreement with the absence of density decrease.

2. The "hot" crystallization peak of irradiated sample is shifted towards lower temperatures by more than $30^{\circ} \mathrm{C}$ and its enthalpy is strongly decreased. This is confirmed by the lower values of melting temperature for the second heating. It indicates that lamellae thickness of crystallites formed from molten state is lower. Indeed, crosslinking prevents chain segments to integer a crystal [28].

\subsubsection{Gel content measurements}

Thick samples became partially insoluble at a dose $\delta_{\mathrm{C}}$ such as $5.0 \mathrm{MGy}<\delta_{\mathrm{G}}<10 \mathrm{MGy}$. From samples having undergone sol-gel transition, the Charlesby-Pinner plot [29] was tried:

$w_{\mathrm{S}}+w_{\mathrm{S}}^{1 / 2}=\frac{G(s)}{2 G(x)}+\frac{10^{7}}{\bar{M}_{\mathrm{W} 0} \cdot G(x) \cdot \delta}$

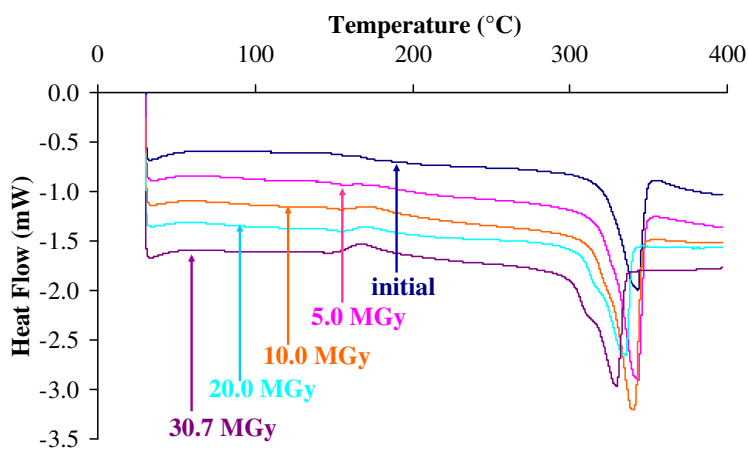

Fig. 10. DSC thermograms of sheaths at different irradiation doses. 

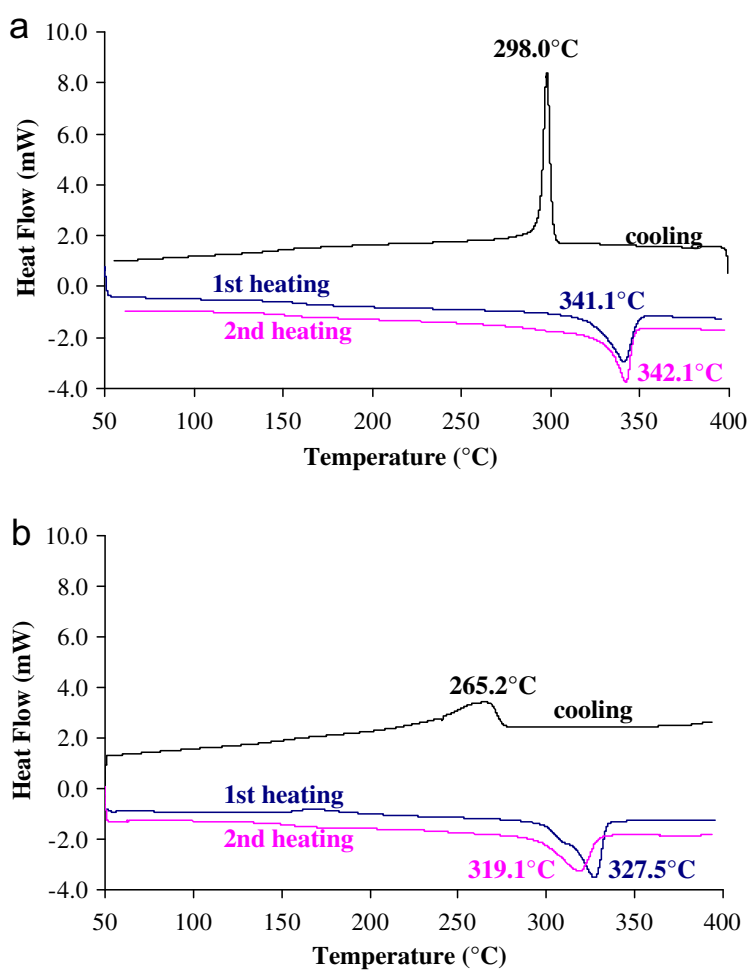

Fig. 11. DSC thermograms of virgin (a) and 30.7 MGy irradiated (b) sheaths during temperature cycles: heating $\left(50-400^{\circ} \mathrm{C}\right)$, cooling $(400-$ $\left.50{ }^{\circ} \mathrm{C}\right)$, heating $\left(50-400{ }^{\circ} \mathrm{C}\right)$.

where

- $w_{\mathrm{S}}=1-w_{\mathrm{I}}$ is the soluble fraction,

- $G(s)$ and $G(x)$ are the respective radiochemical yields for chain scission and crosslinking.

The three points (Fig. 12) are close to a straightline intercepting the origin with a slope close to $1.6 \times$ $10^{7} \mathrm{~Gy}^{-1}$. One deduces:

1. From the ordinate value of intercept at the origin:

$w_{\mathrm{S} 0}+w_{\mathrm{S} 0}^{1 / 2}=\frac{G(s)}{2 G(x)} \sim 0$

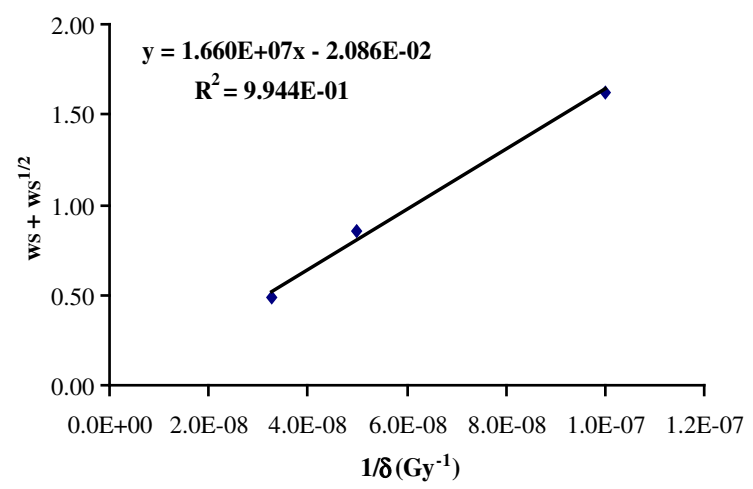

Fig. 12. Radiochemical yields $G(s)$ and $G(x)$ estimation from CharlesbyPinner approach.
So that $G(s) \sim 0$

Let us recall that crosslinking predominates over chain scission when

$\frac{G(s)}{2 G(x)}<2$

Thus crosslinking predominates undoubtedly for thick samples such as sheaths, whereas chain scission predominates in $60 \mu \mathrm{m}$ thin films.

2. The slope of the straightline is:

$\frac{\mathrm{d}\left(w_{\mathrm{S}}+w_{\mathrm{S}}^{1 / 2}\right)}{\mathrm{d} \delta^{-1}}=\frac{10^{7}}{\bar{M}_{\mathrm{W} 0} \cdot G(x)}$

So that $\bar{M}_{W 0} \cdot G(x) \sim 0.61$.

For determining $G(x), M_{\mathrm{W} o}$ is needed but is unfortunately not available here. However, molar mass of PEEK general purpose grades is on the order of $M_{\mathrm{N}} \sim 10-$ $15 \mathrm{~kg} \mathrm{~mol}^{-1}$ and $M_{\mathrm{W}} \sim 25-50 \mathrm{~kg} \mathrm{~mol}^{-1}[2,9,30]$ so that

$G(x) \sim 0.012-0.024$

This result can be tentatively checked from the Saito's theory [20]:

$\frac{1}{\bar{M}_{\mathrm{W}}}-\frac{1}{\bar{M}_{\mathrm{W} 0}}=\frac{s}{2}-2 x$

The crosslinking concentration at the gelation point $\left(M_{\mathrm{W}} \rightarrow \infty\right)$ in the absence of chain scission $(s=0)$ is equal to

$x_{\mathrm{G}}=\frac{1}{2 \bar{M}_{\mathrm{W} 0}}$

$x_{\mathrm{G}}=10^{-7} \times G(x) \times \delta_{\mathrm{G}}$

From gelation point measurement, it is reasonable to consider that $\delta_{\mathrm{G}} \sim(7.5 \pm 2) \mathrm{MGy}$, so that

$\bar{M}_{\mathrm{W} 0} \cdot G(x)=\frac{10^{7}}{2 \times \delta_{\mathrm{G}}}$

$0.53 \leqslant \bar{M}_{\mathrm{W0}} \cdot G(x) \leqslant 0.91$

These values are in good agreement with the starting hypothesis. Although this can not be considered as rigorous evidence, it at least indicates a certain consistency in our results.

\section{Discussion}

PEEK radiochemical ageing in air has been followed on $60 \mu \mathrm{m}$ films and $250 \mu \mathrm{m}$ sheaths. Opposite trends in thin films (predominant chain scission) and in thick sheaths (predominant crosslinking) were observed. Irradiation creates macroradicals reacting mainly by coupling giving thus crosslinking in the absence of oxygen (i.e. for irradiation under vacuum or at high dose rate [31] at which thickness of oxidized layer is very low). When oxygen is present, it adds very fastly to macroradicals, inhibiting thus coupling and orientating the process towards chain scission [32]. The thickness of oxidized layer (denoted by l) can be approximated by: 
$l=2 \sqrt{\frac{D}{k}}$

where

- $D$ is the oxygen diffusion coefficient in the polymer,

- $k$ is the first-order (or pseudo first-order) rate constant of oxygen consumption (i.e. the ratio of oxygen consumption rate and oxygen equilibrium concentration).

$l$ is expected to decrease with this dose rate ( $k$ increase) and crystallinity ratio ( $D$ decrease). Overall, our observations suggest: $60 \mu \mathrm{m}<2 l<250 \mu \mathrm{m}$. In other words, films would be almost fully oxygenated so that they would undergo predominant chain scission. In contrast, thick samples would be oxygenated only in a relatively thin superficial layer (let us recall that only one wall of sheaths is in contact with atmospheric air, the other being in contact with copper conductor) and would undergo predominant crosslinking in their bulk (Fig. 13). This interpretation is supported by ATR microscopy results. The heterogeneity in thick samples can explain at least partially the splitting of melting peak (Fig. 11). The low temperature shoulder (Fig. 8) could be attributed to the oxidized layer where the melting point decreases with irradiation dose.

$\mathrm{C}-\mathrm{H}$ bonds radio-cleavage is a likely reason of crosslinking:
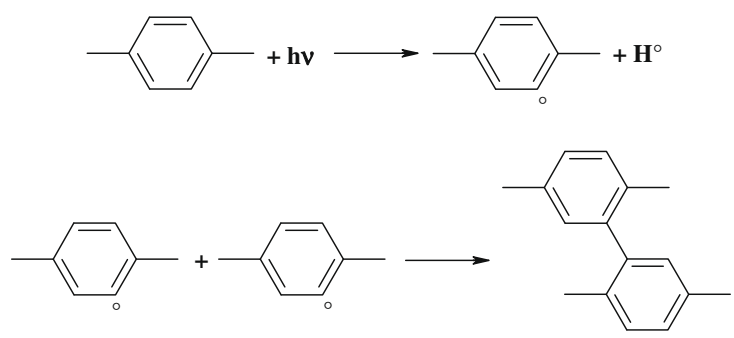

$\mathrm{H}^{\circ}$ radicals abstract probably hydrogen atoms, leading to $\mathrm{H}_{2}$ evolution.

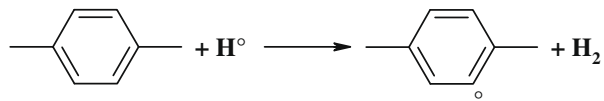

The existence of additions cannot be totally excluded:
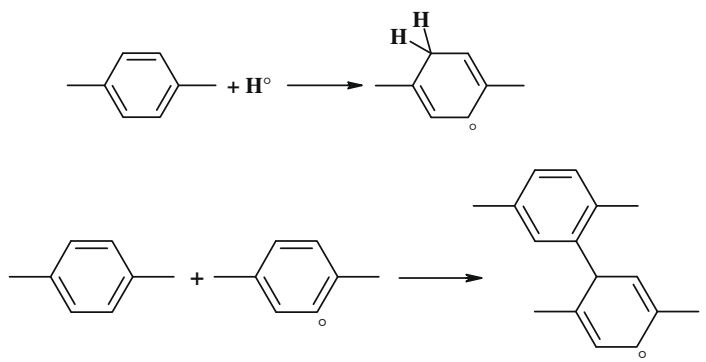

Additions lead also to crosslinking. The resulting cyclohexadienyl radical is resonance stabilized and probably does not propagate the reaction.

The simplest model for PEEK ageing under irradiation in anaerobic conditions could be based on the following mechanistic scheme:

(I) $\mathrm{PH}($ polymer $)+h v \rightarrow \mathrm{P}^{\circ}$ (radicals) $+1 / 2 \mathrm{H}_{2} \quad r_{i}$

$$
=10^{-7} G\left(P^{\circ}\right) \cdot I
$$

(II') $\mathrm{P}_{1}^{\circ}+\mathrm{P}_{2} \mathrm{H} \rightarrow \mathrm{P}_{1} \mathrm{H}+\mathrm{P}_{2}^{\circ} \quad k_{\mathrm{p}}$

(III) $\mathrm{P}^{\circ}+\mathrm{P}^{\circ} \rightarrow \mathrm{P}-\mathrm{P}+x$ (coupling) $\quad k_{4}$

In the above scheme, reaction II is only a transfer of the radical site without direct incidence on kinetics. However, it plays a major role in allowing the reactive site to diffuse by the so called valence migration process [33] favouring thus termination despite the relatively low segmental mobility $100 \mathrm{~K}$ below polymer glass transition temperature. Plot of radical concentration versus dose from ESR measurements at $77 \mathrm{~K}$ on irradiated PEEK samples [34] displays a negative concavity indicating the existence of a termination process.

$G\left(\mathrm{P}^{\circ}\right)$ can be estimated from:

1. Kinetic analysis of Heiland's result [34]. The rate law is:

$\frac{\mathrm{d}\left[\mathrm{P}^{\circ}\right]}{\mathrm{d} t}=r_{i}-2 k_{4}\left[\mathrm{P}^{\circ}\right]^{2}$

At steady state : $\left[\mathrm{P}^{\circ}\right]_{\infty}=\frac{r_{i}}{2 k_{4}}$
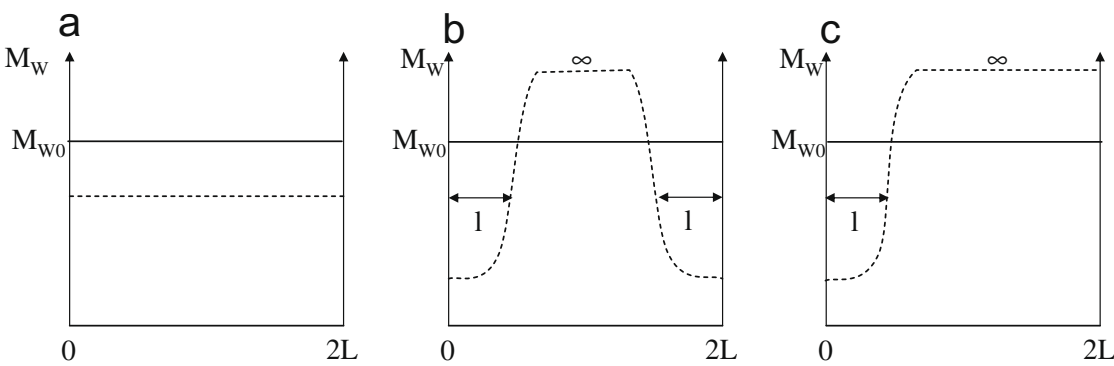

Fig. 13. Schematic representation of the $M_{\mathrm{W}}$ profiles in a thick PEEK sample submitted to irradiation in the presence of oxygen before (full line) and after irradiation (dashed line). (a) Case of the films (two walls in contact with air). (b) General case (two walls in contact with air). (c) Case of sheaths investigated in this study (one wall in contact with air). 
So $\frac{\mathrm{d}\left[\mathrm{P}^{\circ}\right]}{\mathrm{d} t}=2 k_{4}\left(\left[\mathrm{P}^{\circ}\right]_{\infty}^{2}-\left[\mathrm{P}^{\circ}\right]^{2}\right)$

The integration gives $\left[\mathrm{P}^{\circ}\right]=\frac{\exp \left(4 k_{4}\left[\mathrm{P}^{\circ}\right]_{\infty} t\right)-1}{\exp \left(4 k_{4}\left[\mathrm{P}^{\circ}\right]_{\infty} t\right)+1}$

$$
\cdot\left[\mathrm{P}^{\circ}\right]_{\infty}
$$

Graphical measure gives : $\left(\frac{d\left[P^{\circ}\right]}{\mathrm{d} t}\right)_{t \rightarrow 0}=r_{i}$

$$
\sim 2.5 \times 10^{-8} \mathrm{~mol} \mathrm{l}^{-1} \mathrm{~s}^{-1}
$$

So that $G\left(\mathrm{P}^{\circ}\right) \sim 0.25$. It is noteworthy that this value is considerably lower than for aliphatic polymers, for instance $G\left(\mathrm{P}^{\circ}\right)=8$ for PE [35] what illustrates the well-known stabilizing effect of aromatic groups [36-39].

2. In the absence of other termination (or radical rearranging) reactions, the kinetic analysis of the scheme leads to the following expression of the crosslinking rate:

$\frac{\mathrm{d} x}{\mathrm{~d} t}=\frac{r_{i}}{2}=k_{4}\left[\mathrm{P}^{\circ}\right]^{2}$

Thus $G(x)=\frac{G_{i}}{2}=\frac{G\left(\mathrm{P}^{\circ}\right)}{2}$

Since : $G(x)=0.012-0.024$

so that $G\left(P^{\circ}\right) \sim 0.024-0.048$

The fact that its yield $(0.024-0.048)$ is $5-10$ times lower than the radical yield $(0.25)$ would indicate the existence of other termination than coupling, corresponding to 80$90 \%$ of the whole termination events. The formation of dibenzofuran derivates [7] could be a possible explanation but this question remains open.

Irradiation is expected to create crystals defects decreasing the melting point. After 30.7 MGy irradiation, $15 \mathrm{~K}$ drop is effectively observed for the melting endotherm (Fig. 10). According to Flory:

$\frac{1}{T_{\mathrm{M}}}-\frac{1}{T_{\mathrm{M} \infty}}=-\frac{R}{\Delta H_{\mathrm{M} \infty}} \cdot \ln (1-y)$

where $T_{\mathrm{M} \infty}$ is the equilibrium melting point, $\Delta H_{\mathrm{M} \infty}$ the melting enthalpy of infinite crystal and y the molar fraction of crystalline defects. This relationship can be transposed into

$\frac{1}{T_{\mathrm{M}}}-\frac{1}{T_{\mathrm{M} 0}}=-\frac{R}{\Delta H_{\mathrm{M} \infty}} \cdot \ln \left(\frac{1-y}{1-y_{0}}\right)$

$T_{\mathrm{Mo}}$ and $y_{0}$ corresponding to the initial state. Assimilating the initial molar fraction of defects to the initial molar fraction of monomers units in the amorphous phase $\left(y_{0}=0.75\right)$, and derivating the above expression, one obtains

$\frac{\mathrm{d} y}{\mathrm{~d} \delta}=-\frac{\Delta H_{\mathrm{M} \infty}}{R T_{\mathrm{M} 0}^{2}} \cdot\left(1-y_{0}\right) \cdot \frac{\mathrm{d} T_{\mathrm{M}}}{\mathrm{d} \delta}$

and $G(y)=-10^{7} \cdot \frac{\Delta H_{\mathrm{M} \infty}}{R T_{\mathrm{M} 0}^{2}} \cdot\left(1-y_{0}\right) \cdot \frac{\mathrm{d} T_{\mathrm{M}}}{\mathrm{d} \delta}$
Taking $\Delta H_{\mathrm{M}_{\infty}}=37500 \mathrm{~J} \mathrm{~mol}^{-1}$ [22], $G(y) \sim 0.012$ is obtained. The fact that this value is lower than radical formation yield indicates that only a few part of radical affects the crystalline morphology.

When it is present, oxygen reacts fastly with primary aryl radicals to give peroxyl ones, preventing them from crosslinking. Peroxy radicals are not very reactive, neither for hydrogen abstracting nor for adding to aromatic nuclei. In contrast, they can participate to bimolecular combinations giving relatively more reactive phenoxy radicals:<smiles></smiles><smiles>CCCc1ccc([N+](=O)[O-])c([O-])c1</smiles>

Hydrogen abstraction by phenoxy radicals will give a phenolic group:

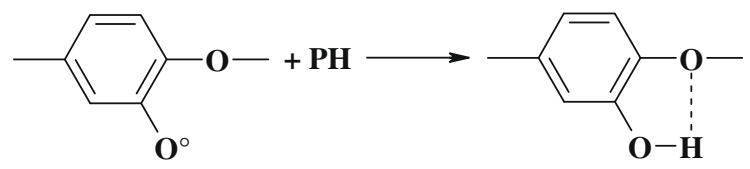

(A)

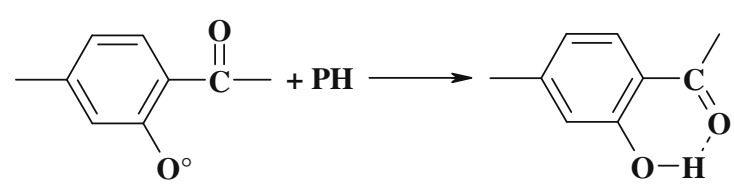

(B)

$\mathrm{OH}$ groups are expected to be intramolecularly hydrogen bonded through a 5 or 6 members cycle. Orthohydroxybenzophenones of (B) type are strong UV absorbers [40] what explains the observed yellowing (curves are not presented in this paper).

Chains scission could be tentatively explained by rearrangements of a small part of phenoxy radicals, for instance:

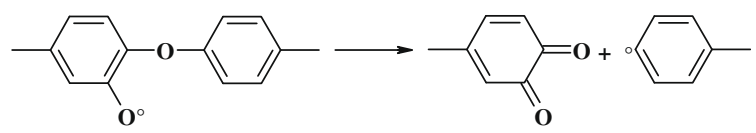

(C)

Conjugated diketones (C) are also expected to be strongly absorbing in the near UV and at c.a. $1690 \mathrm{~cm}^{-1}$ (see FTIR results). Primary chain scissions can also be envisaged: 


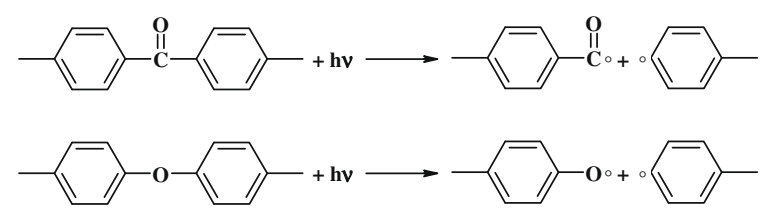

In the presence of oxygen, a new mechanistic scheme must be used. The simplest one is very close to the Basic Autooxidaiton Scheme extensively studied by Gillen and Clough [41-43]. It tries to take into account the above reactions:

(I) $\mathrm{PH}($ polymer $)+h v \rightarrow \mathrm{P}^{\circ}$ (radicals $)+\gamma_{\mathrm{s}} \cdot s \quad r_{i}$

$$
=10^{-7} \mathrm{G}\left(\mathrm{P}^{\circ}\right) \cdot I
$$

(II) $\mathrm{P}^{\circ}+\mathrm{O}_{2} \rightarrow \mathrm{POO}^{\circ} \quad k_{2}$

$\left(\mathrm{II}^{\prime}\right) \quad \mathrm{P}_{1}^{\circ} \rightarrow \mathrm{P}_{2}^{\circ}+\gamma_{X} \cdot x \quad k_{\mathrm{P}^{\prime}}$

(III) $\mathrm{POO}^{\circ}+\mathrm{PH} \rightarrow \mathrm{POOH}+\mathrm{P}^{\circ} \quad k_{3}$

(IV) $\mathrm{P}^{\circ}+\mathrm{P}^{\circ} \rightarrow$ inactive products $+x$ (coupling) $\quad k_{4}$

(V) $\mathrm{P}^{\circ}+\mathrm{POO}^{\circ} \rightarrow$ inactive products $+x$ (coupling) $k_{5}$

(VI) $\mathrm{POO}^{\circ}+\mathrm{POO}^{\circ} \rightarrow$ inactive products $\quad k_{6}$

- The reaction (VI) is a kinetically equivalent to a more complex mechanism of $\mathrm{POO}^{\circ}+\mathrm{POO}^{\circ}$ termination involving, as mentioned above, $\mathrm{PO}^{\circ}$ radicals and their decomposition into ketones, alcohols, chain scissions etc. [44].

- The $\left(\mathrm{II}^{\prime}\right)$ reaction corresponds to valence migration or cyclohexadienyl formation as previously proposed.

Although this scheme is an oversimplification, it provides a way to determine some kinetic parameters characterizing the PEEK oxidation. In a thick sample, oxidation is kinetically controlled by oxygen diffusion. Hence, the variation of the oxygen concentration in a depth $\mathrm{x}$ elementary layer would be given by:

$\frac{\partial\left[\mathrm{O}_{2}\right]}{\partial t}=D_{\mathrm{O}_{2}} \frac{\partial^{2}\left[\mathrm{O}_{2}\right]}{\partial x^{2}}-k_{2}\left[\mathrm{P}^{\circ}\right]\left[\mathrm{O}_{2}\right]+k_{6}\left[\mathrm{POO}^{\circ}\right]^{2}$

The analytical solution of this scheme in steady state using the classical assumption $k_{5}^{2}=4 k_{4} k_{6}$ gives the expression of oxidation rate $r_{\mathrm{OX}}$ :

$r_{\mathrm{OX}}=D_{\mathrm{O}_{2}} \frac{\partial^{2}\left[\mathrm{O}_{2}\right]}{\partial x^{2}}=\frac{\alpha\left[\mathrm{O}_{2}\right]}{1+\beta\left[\mathrm{O}_{2}\right]}$

where $\alpha=k_{2} \sqrt{\frac{r_{i}}{2 k_{4}}}$

and $\beta=\frac{k_{2}}{k_{3}[\mathrm{PH}]} \sqrt{\frac{k_{6}}{k_{4}}}$
The boundary conditions are:

- at $t=0:\left[\mathrm{P}^{\circ}\right]_{0}=\left[\mathrm{POO}^{\circ}\right]_{0}=0,[\mathrm{POOH}]=[\mathrm{POOH}]_{0},[\mathrm{PH}]=$ $[\mathrm{PH}]_{0}[45]$,

- at $t=0$, every $x:\left[\mathrm{O}_{2}\right]=\left[\mathrm{O}_{2}\right]_{\mathrm{s}}$,

- at $x=0$, at every $t:\left[\mathrm{O}_{2}\right]=\left[\mathrm{O}_{2}\right]_{\mathrm{S}}$ (sample surface).

- $\mathrm{D}_{\mathrm{O}_{2}}$ is the oxygen diffusion coefficient in PEEK amorphous phase. The compilation by Van Krevelen [46] suggests $\mathrm{D}_{\mathrm{O}_{2}} \sim 1 \times 10^{-11} \mathrm{~m}^{2} \mathrm{~s}^{-1}$ (assuming that PEEK amorphous phase behaves as bisphenol A polycarbonate one).

- $\left[\mathrm{O}_{2}\right]$ the oxygen concentration in amorphous phase given by Henry's law:

$\left[\mathrm{O}_{2}\right]_{\mathrm{C}}=s_{\mathrm{O}_{2}} \times \mathrm{P}_{\mathrm{O}_{2}}$

- $s_{\mathrm{O}_{2}}$ is the oxygen solubility in PEEK amorphous phase. The compilation for glassy amorphous polymers [39] suggests that it ranges between $2 \cdot 10^{-8}$ and $4.10^{-8}$ mol ${ }^{-1} \mathrm{~Pa}^{-1}$.

Two asymptotic kinetic regimes can be defined:

- At very low oxygen pressure, i.e. : $\left[\mathrm{O}_{2}\right]_{\mathrm{S}}<<\beta^{-1}$

one has in steady state : $r_{\mathrm{OX}}=D_{\mathrm{O}_{2}} \frac{\partial^{2}\left[\mathrm{O}_{2}\right]}{\partial x^{2}}=\alpha\left[\mathrm{O}_{2}\right]$

- Under oxygen excess : $\left[\mathrm{O}_{2}\right]_{S}>>\beta^{-1}$

one has in steady state : $r_{\mathrm{OX}}=D_{\mathrm{O}_{2}} \frac{\partial^{2}\left[\mathrm{O}_{2}\right]}{\partial x^{2}}=\frac{\alpha}{\beta}$

The transition between these regimes is very progressive. One can define arbitrarily a "critical oxygen concentration" in the polymer amorphous phase separating the two domains: $\left[\mathrm{O}_{2}\right]_{\mathrm{C}}=q \cdot \beta^{-1}$ with $q \sim 10$. For $\left[\mathrm{O}_{2}\right]_{\mathrm{S}}>\left[\mathrm{O}_{2}\right]_{\mathrm{c}}$, it is considered that oxygen is in excess and scavenges every $\mathrm{P}^{\circ}$ radical to give a $\mathrm{POO}^{\circ}$. Termination results therefore only from $\mathrm{POO}^{\circ}+\mathrm{POO}^{\circ}$ reaction [47]. In this regime, the oxidation rate $r_{\mathrm{OX}}=\alpha / \beta$ is independent of the oxygen concentration. The hydroxyl concentration profile (Fig. 9) would thus indicate that $\left[\mathrm{O}_{2}\right]>\left[\mathrm{O}_{2}\right]_{\mathrm{C}}$ in the plateau length $l_{\mathrm{P}}$ expressed by:

$l_{\mathrm{P}}=\sqrt{\frac{2 D_{\mathrm{O}_{2}} \beta}{\alpha} \cdot\left(\left[\mathrm{O}_{2}\right]_{\mathrm{S}}-\left[\mathrm{O}_{2}\right]_{\mathrm{C}}\right)}$

$l_{\mathrm{P}}=\sqrt{\frac{2 D_{\mathrm{O}_{2}} \beta}{\alpha} \cdot\left[\mathrm{O}_{2}\right]_{\mathrm{S}}} \times \sqrt{1-\frac{\left[\mathrm{O}_{2}\right]_{\mathrm{C}}}{\left[\mathrm{O}_{2}\right]_{\mathrm{S}}}}$

Except for a coincidence : $\left[\mathrm{O}_{2}\right]_{\mathrm{C}}<<\left[\mathrm{O}_{2}\right]_{\mathrm{S}}$.

so that $\frac{\beta}{\alpha}=\frac{l_{\mathrm{P}}^{2}}{2 \cdot D_{\mathrm{O}_{2}} \cdot s_{\mathrm{O}_{2}} \cdot \mathrm{P}_{\mathrm{O}_{2}}}$

Using the above mentioned oxygen transport parameters, and $l_{\mathrm{P}} \sim 50 \mu \mathrm{m}$, one obtains $\beta / \alpha \sim 10^{6}-10^{7}$ and the oxygen consumption rate in regime of oxygen excess:

$r_{\mathrm{S}}=\frac{\alpha}{\beta}=k_{3}[\mathrm{PH}] \sqrt{\frac{r_{i}}{k_{6}}} \sim 10^{-6}-10^{-7} \mathrm{~mol} \mathrm{l}^{-1} \mathrm{~s}^{-1}$ 
where:

- $k_{3}$ is the rate constant for $\mathrm{POO}^{\circ}+\mathrm{PH} \rightarrow \mathrm{POOH}+\mathrm{P}^{\circ}$ propagation,

$-k_{6}$ is the rate constant for $\mathrm{POO}^{\circ}+\mathrm{POO}^{\circ} \rightarrow$ inactive products termination,

- $[\mathrm{PH}]$ is the oxidizable substrate concentration: $[\mathrm{PH}] \sim 13 \mathrm{~mol} \mathrm{l}^{-1}$,

- $r_{i}$ is the initiation rate depending on the radiochemical yield of radical formation $G\left(\mathrm{P}^{\circ}\right)$ :

$r_{i}=10^{-7} \times G\left(\mathrm{P}^{\circ}\right) \times I$

$G\left(\mathrm{P}^{\circ}\right)$ value can be estimated from the curves of alkyl radical growth $\left(G\left(\mathrm{P}^{\circ}\right)=0.25\right)$, sol-gel analysis $\left(G\left(\mathrm{P}^{\circ}\right)=\right.$ 0.024-0.048), or the rate of formation of all stable oxidation products: since the radical yield of initiation cannot be lower than the radiochemical yield of product formation, $G\left(\mathrm{P}^{\circ}\right) \geqslant G(\mathrm{OH})+G(\mathrm{CO})$, i.e. $G\left(\mathrm{P}^{\circ}\right) \geqslant 0.42$. Let us note that a better agreement between this estimation and the one from ESR measurement (0.25) could be obtained using a higher value of molar absorptivity for hydroxyl products. For example, $901 \mathrm{~mol}^{-1} \mathrm{~cm}^{-1}$ was proposed by Carlsson [48]. According to our own experience on phenolic antioxidants in PP [49], a value close to $100-1101 \mathrm{~mol}^{-1} \mathrm{~cm}^{-1}$ could even be envisaged.

Keeping $G\left(\mathrm{P}^{\circ}\right)=0.25$, one obtains: $r_{i}=1.7 \times 10^{-7}$ $\mathrm{mol} \mathrm{l}^{-1} \mathrm{~s}^{-1}$ and $k_{3} / k_{6}^{1 / 2}=2 \times 10^{-4}-2 \times 10^{-5} \mathrm{l}^{1 / 2} \mathrm{~mol}^{-1 / 2}$ $\mathrm{s}^{-1 / 2} . k_{3} / k_{6}^{1 / 2}$ parameter characterizes the intrinsic substrate oxidizability independently of the initiation mode. PP value $\left(8 \times 10^{-4} \mathrm{l}^{1 / 2} \mathrm{~mol}^{-1 / 2} \mathrm{~s}^{-1 / 2}\right.$ at $\left.60^{\circ} \mathrm{C}\right)$ has the same order of magnitude than PEEK one. This relatively surprising result can be explained as follows:

Propagation reaction $\mathrm{POO}^{\circ}+\mathrm{PH} \rightarrow \mathrm{POOH}+\mathrm{P}^{\circ}$ is probably not diffusion controlled because every $\mathrm{POO}^{\circ}$ radicals can find substrate molecules in its immediate vicinity. Thus, $\mathrm{k}_{3}$ depends on the intrinsic reactivity of $\mathrm{POO}^{\circ}$ towards $\mathrm{C}-\mathrm{H}$ bond i.e. on the dissociation energy of the broken $\mathrm{C}-\mathrm{H}$ bonds [50]. Given $\mathrm{C}-\mathrm{H}$ bond are considerably stronger for aromatic $\left(\Delta H_{1} \sim 400-450 \mathrm{~kJ} \mathrm{~mol}^{-1}\right)$ [51] than aliphatic $\mathrm{C}-\mathrm{H}\left(\Delta H_{1} \sim 380 \mathrm{~kJ} \mathrm{~mol}^{-1}\right)$ compounds [48], one expects

$k_{3}(\mathrm{PEEK})<<k_{3}(\mathrm{PP})$

Termination reaction between two $\mathrm{POO}^{\circ}$ involves relatively rare species and is thus expected to be diffusion controlled, i.e. dependent on the polymer segmental mobility. Since the PP amorphous phase is in rubbery state whereas the PEEK one is in glassy state, and since termination is minimised by the impossibility of radical disproportionnation, one expects

$k_{6}(\mathrm{PEEK})<<k_{6}(\mathrm{PP})$

Thus, the difference in termination rates compensates the difference in propagation ones.

Let us now consider the consequences of polymer oxidative degradation. The radiochemical yield $G(s)$ of primary chain scission would be small enough to permit predominant crosslinking in anaerobic conditions. According to Saito's equations [20], crosslinking predominates if:

$G(s)<4 \cdot G(x)$
This condition is here largely fulfilled. By supposing that crosslinking is totally inhibited in well-oxygenated samples, molar mass variations are given by:

$\frac{1}{\bar{M}_{\mathrm{N}}}-\frac{1}{\bar{M}_{\mathrm{N} 0}}=s=10^{-7} \times G(s) \times \delta$

As previously found: $G(s) \sim 0.012$

$\frac{1}{\bar{M}_{\mathrm{N}}}=\frac{1}{\bar{M}_{\mathrm{N} 0}}+1.2 \times 10^{-9} \times \delta$

Amorphous PEEK embrittlement was observed at about 8 MGy dose [52] so that

$s=\frac{1}{\bar{M}_{\mathrm{N}}}-\frac{1}{\bar{M}_{\mathrm{N} 0}} \sim 0.01 \mathrm{~mol} \mathrm{~kg}^{-1}$

Since embrittlement is linked to the existence of a critical chain length $\left(M_{\mathrm{N}}=M_{\mathrm{C}}^{\prime}\right)$, it comes

$\bar{M}_{\mathrm{C}}^{\prime}=\frac{\bar{M}_{\mathrm{N} 0}}{1+0.01 \cdot \bar{M}_{\mathrm{N} 0}}$

As previously proposed, the following inequality seems reasonable:

$10 \mathrm{~kg} \mathrm{~mol}{ }^{-1} \leqslant \bar{M}_{\mathrm{N}_{0}} \leqslant 25 \mathrm{~kg} \mathrm{~mol}^{-1}$

It comes : $8 \mathrm{~kg} \mathrm{~mol}^{-1} \leqslant \bar{M}_{\mathrm{C}}^{\prime} \leqslant 20 \mathrm{~kg} \mathrm{~mol}^{-1}$

The number of chain scissions per initial number average chain is

$C=s \times \bar{M}_{\mathrm{N}_{0}}=10^{-2} \times \bar{M}_{\mathrm{N}_{0}}$

$0.1 \leqslant C \leqslant 0.25$

which means that embrittlement occurs at very low conversion of the chain scission process, i.e. less than one scission per 4 chains.

\section{Conclusions}

PEEK radiochemical behaviour can be first explained by its aromatic character which is doubly favourable:

- Primary radiochemical events, presumably radiolytic C$\mathrm{H}$ bonds cleavage, have a radiochemical yield less than 0.5 , i.e. 5-50 times lower than for aliphatic polymers, because aromatic groups are able to dissipate a great part of the absorbed energy into reversible processes (fluorescence, phosphorescence ...). As a consequence, PEEK belongs to the category of relatively stable polymers under irradiation.

- The propagation rate constant of hydrogen abstraction by peroxy radicals $\left(k_{3}\right)$ is a decreasing function of the $\mathrm{C}-\mathrm{H}$ bond dissociation energy, that takes a high value for aromatic hydrogen.

These positive effects are partially counterbalanced by the relatively low termination rate linked to the low segmental mobility in glassy state. It is noteworthy that $\mathrm{P}^{\circ}+\mathrm{P}^{\circ}$ termination (which leads to crosslinking when oxygen is lacking) is more efficient than expected because $\mathrm{P}^{\circ}$ 
radicals can diffuse independently of segmental mobility by the valence migration process $\left(\mathrm{P}_{1}^{\circ}+\mathrm{P}_{2} \mathrm{H} \rightarrow \mathrm{P}_{1} \mathrm{H}+\mathrm{P}_{2}^{\circ}\right)$.

Chain scissions were found to predominate in well-oxygenated samples ( $60 \mu \mathrm{m}$ thickness). A Fox-Flory constant value derived from theoretical considerations enabled determination of the radiochemical yield of chain scission for PEEK: $G(s) \sim 0.012$. Although this value is relatively low, its consequences on glass transition decrease are dramatic: $\Delta T_{\mathrm{g}} \sim-7 \mathrm{~K}$ for a $30.7 \mathrm{MGy}$ irradiation.

In the conditions under study (oxygen pressur$\mathrm{e}=3.0 \times 10^{4} \mathrm{~Pa}$ ), oxidation kinetics is in the oxygen excess regime in the superficial layers. It means that $\mathrm{P}^{\circ}$ radicals are fastly converted into $\mathrm{POO}^{\circ}$ ones so that crosslinking resulting from $\mathrm{P}^{\circ}+\mathrm{P}^{\circ}$ termination reactions is inhibited.

Results from ATR microscopy confirmed that oxidation is diffusion limited in thick samples $(250 \mu \mathrm{m})$ where crosslinking predominates in the sample core. Let us precise that measurements of Thickness of Oxidized Layer for PEEK were not available in literature to our knowledge whereas this feature is fundamental for understanding the ageing behaviour [53]. Here, it was used to assess some kinetic parameters characterizing the oxidation of PEEK using the yield of radical formation estimated from the radical growth kinetics under irradiation at $77 \mathrm{~K}$.

\section{Acknowledgements}

EDF R\&D is gratefully acknowledged for financial support.

Hans Ooms and Benoit Brichard from SCK CEN Lab (Mol, Belgium) for having performed irradiations.

Serge Colombier, Thierry Jorand, Jean-Louis Pons (Pirelli Prysmian, Sens, France) for having supplied PEEK pellets and sheaths.

\section{Appendix A. Fox-Flory constant}

Three ways were implemented to assess the PEEK FoxFlory constant $k_{\mathrm{FF}}$ :

1 . The first one is derived from the "free volume" theory. If $T_{\mathrm{g} \infty}$ is the $T_{\mathrm{g}}$ value for an hypothetical polymer of infinite molar mass, the volume excess of a finite molar mass polymer at $T_{\mathrm{g}_{\infty}}$ is proportional to the number of chain ends, that gives

$k_{\mathrm{FF}}=\frac{2 \rho V_{\text {end }}}{\Delta \alpha}$

where

- $\rho$ is the density of amorphous polymer,

- $V_{\text {end }}$ is the volume excess of one chain end,

- $\Delta \alpha=\alpha_{\mathrm{L}}-\alpha_{\mathrm{g}}$ is the difference between volumic expansion coefficients in rubber/liquid state $\left(\alpha_{\mathrm{L}}\right)$ and glassy state $\left(\alpha_{\mathrm{g}}\right)$.

The estimation is based on two hypotheses according to which, in a restricted family of polymers having close molecular structures:

- The Simha and Boyer rule [54] is valid: $\Delta \alpha_{i} \cdot T_{g i}=$ constant ( $i$ being a given polymer).
- $V_{\text {end }}$ is almost independent of the polymer structure.

Here, PEEK is compared to the PC. One can write

$\frac{\left(k_{\mathrm{FF}}\right)_{\mathrm{PEEK}}}{\left(k_{\mathrm{FF}}\right)_{\mathrm{PC}}}=\frac{\rho_{\mathrm{PEEK}}}{\rho_{\mathrm{PC}}} \cdot \frac{\left(T_{g_{\infty}}\right)_{\mathrm{PEEK}}}{\left(T_{\mathrm{g}_{\infty}}\right)_{\mathrm{PC}}}$

where

- $\left(k_{\mathrm{FF}}\right)_{\mathrm{PC}}=187 \mathrm{~K} \mathrm{~mol} \mathrm{~kg}^{-1}[55]$,

- $\rho_{\mathrm{PC}}$ is close to $1200 \mathrm{~kg} \mathrm{~m}^{-3}$,

- $\rho_{\text {PEEK }}$ (for the amorphous phase) is close to $1260 \mathrm{~kg} \mathrm{~m}^{-3}$,

- $\left(T_{\mathrm{g}_{\infty}}\right)_{\mathrm{PC}}$ is equal to $434 \mathrm{~K}$ [52],

- $\left(T_{\mathrm{g} \infty}\right)_{\text {PEEK }}$ is unknown but is probably close to $420 \mathrm{~K}$.

which gives $\left(k_{\mathrm{FF}}\right)_{\text {PEEK }}=190 \mathrm{~K} \mathrm{~mol} \mathrm{~kg}^{-1}$.

2. The second is derived from a classical copolymer law in which chain ends are considered as comonomers:

$\frac{\bar{M}_{\mathrm{N}}}{T_{\mathrm{g}}}=\frac{\bar{M}_{\mathrm{N}}}{T_{\mathrm{g} \infty}}+2 b$

i.e. $T_{g}=\frac{T_{g_{\infty}}}{1+\frac{2 b \cdot T_{g \infty}}{\bar{M}_{\mathrm{N}}}}$

$b$ being the chain end contribution to $M_{\mathrm{N}} \cdot T_{\mathrm{g}}^{-1}$. Classical approximations give

$T_{g}=T_{g_{\infty}}-\frac{2 b \cdot T_{g_{\infty}}^{2}}{\bar{M}_{\mathrm{N}}}$

so that $k_{\mathrm{FF}}=2 b \cdot T_{\mathrm{g} \infty}^{2}$

Assuming that $b$ is structure independent in a reasonably restricted polymer family, one can write

$\frac{\left(k_{\mathrm{FF}}\right)_{\mathrm{PEEK}}}{\left(k_{\mathrm{FF}}\right)_{\mathrm{PC}}}=\left(\frac{\left(T_{\mathrm{g} \infty}\right)_{\mathrm{PEEK}}}{\left(T_{\mathrm{g}_{\infty}}\right)_{\mathrm{PC}}}\right)^{2}$

i.e. $\left(k_{\mathrm{FF}}\right)_{\mathrm{PEEK}}=178 \mathrm{~K} \mathrm{~mol} \mathrm{~kg}^{-1}$

3. The third way is an empirical relationship proposed by Bicerano [52]:

$T_{g}=T_{g_{\infty}}-0.002715 \cdot \frac{T_{\mathrm{g}_{\infty}}^{3}}{\bar{M}_{\mathrm{N}}}$

The direct calculation gives: $\left(k_{\mathrm{FF}}\right)_{\mathrm{PEEK}}=201 \mathrm{~K} \mathrm{~mol} \mathrm{~kg}^{-1}$. Nevertheless, it seems that significant discrepancies exist between this model and experimental results reported in the monograph, so that another estimation is derived:

$\frac{\left(k_{\mathrm{FF}}\right)_{\mathrm{PEEK}}}{\left(k_{\mathrm{FF}}\right)_{\mathrm{PC}}}=\left(\frac{\left(T_{\mathrm{g} \infty}\right)_{\mathrm{PEEK}}}{\left(T_{\mathrm{g} \infty}\right)_{\mathrm{PC}}}\right)^{3}$

that gives $\left(k_{\mathrm{FF}}\right)_{\text {PEEK }}=169 \mathrm{~K} \mathrm{~mol} \mathrm{~kg}^{-1}$

Finally, a median value is chosen:

$\left(k_{\mathrm{FF}}\right)_{\text {PEEK }}=185 \mathrm{~K} \mathrm{~mol} \mathrm{~kg}^{-1}$.

\section{References}

[1] Clough RL, Gillen KT, Dole M. Irradiation effects on polymers, vol. 3. London: Elsevier Applied Science; 1991.

[2] Jonas A, Legras R. Thermal stability and crystallization of poly(aryl ether ether ketone). Polymer 1991;32(15):2691-706. 
[3] Day M, Cooney JD, Wiles DM. The thermal stability of poly(arylether-ether-ketone) as assessed by thermogravimetry. J. Appl. Polym. Sci. 1989;38(2):323-37.

[4] Day M, Suprunchuk T, Cooney JD, Wiles DM. Thermal degradation of poly(aryl-ether-ether-ketone) (PEEK): a differential scanning calorimetry study. J. Appl. Polym. Sci. 1988;36(5):1097-106.

[5] Day M, Cooney JD, Wiles DM. The kinetics of the oxidative degradation of poly(aryl-ether-ether-ketone) (PEEK). Thermochim. Acta 1989;147(1):189-97.

[6] Day M, Cooney JD, Wiles DM. The thermal degradation of poly(arylether-ether-ketone) (PEEK) as monitored by pyrolysis-GC/MS and TG/MS. J. Anal. Appl. Pyrol. 1990;18(2):163-73.

[7] Hay JN, Kemmish DJ. Thermal decomposition of poly(aryl ether ketones). Polymer 1987;28(12):2047-51.

[8] Hegazy ESA, Sasuga T, Seguchi T. Irradiation effects on aromatic polymers: 3 . Changes in thermal properties by gamma irradiation. Polymer 1992;33(14):2911-4.

[9] Vaughan AS, Stevens GC. On crystallization, morphology and radiation effects in poly(ether ether ketone). Polymer 1995;36(8):1531-40.

[10] Sagomonyants KB, Jarman-Smith ML, Devine JN, Aronow MS, Gronowicz GA. The in vitro response of human osteoblasts to polyetheretherketone (PEEK) substrates compared to commercially pure titanium. Biomaterials 2008;29(11):1563-72.

[11] Bas C, Grillet AC, Thimon F, Albérola ND. Crystallization kinetics of poly(aryl ether ether ketone): time-temperature-transformation and continuous-cooling-transformation diagrams. Eur. Polymer J. 1995;31(10):911-21.

[12] Naffakh M, Ellis G, Gómez MA, Marco C. Thermal decomposition of technological polymer blends 1 . Poly(aryl ether ether ketone) with a thermotropic liquid crystalline polymer. Polym. Degrad. Stab. 1999;66(3):405-13.

[13] Rivaton A, Lalande D, Gardette JL. Influence of the structure on the $\gamma$ irradiation of polypropylene and on the post-irradiation effects. Nucl. Instrum. Methods Phys. Res. B 2004;222(1-2):187-200.

[14] Rivaton A, Gardette JL. Photodegradation of polyethersulfone and polysulfone. Polym. Degrad. Stab. 1999;66(3):385-403.

[15] Carlsson DJ, Wiles DM. Photooxidation of polypropylene films. IV. surface changes studied by attenuated total reflection spectroscopy. Macromolecules 1971;4(2):174-9.

[16] Lacoste J, Carlsson DJ. Gamma-, photo-, and thermally-initiated oxidation of linear low density polyethylene: a quantitative comparison of oxidation products. J. Polym. Sci. A: Polym. Chem. 1992;30(3):493-500.

[17] Lacoste J, Vaillant D, Carlsson DJ. Gamma-, photo-, and thermallyinitiated oxidation of isotactic polypropylene. J. Polym. Sci. A: Polym. Chem. 1993;31(3):715-22.

[18] Rugg FM, Smith JJ, Bacon RC. Infrared spectrophotometric studies on polyethylene. II. oxidation. J. Polym. Sci. 1954;13(72):535-47.

[19] Fox TG, Flory PJ. Second-order transition temperatures and related properties of polystyrene. I. Influence of molecular weight. J. Appl. Phys. 1950;21(6):581-91.

[20] Saito O. On the Effect of high energy radiation to polymers I. Crosslinking and degradation. J. Phys. Soc. Jpn. 1958;13:198-206.

[21] Robelin-Souffaché E, Rault J. Origin of the long period and crystallinity in quenched semicrystalline polymers. 1. Macromolecules 1999;22(9):3581-94

[22] Blundell DJ, Osborn BN. The morphology of poly(aryl-ether-etherketone). Polymer 1983;24(8):953-8.

[23] Lee Y, Porter RS. Double-melting behavior of poly(ether ether ketone). Macromolecules 1987;20(6):1336-41.

[24] Choe CR, Lee KH. Nonisothermal crystallization kinetics of poly(etheretherketone) (PEEK). Polym. Eng. Sci. 1989;29(12):801-5.

[25] Fayolle B, Richaud E, Colin X, Verdu J. Review: degradation-induced embrittlement in semi-crystalline polymers having their amorphous phase in rubbery state. J. Mater. Sci. 2008;43(22):6999-7012.

[26] Vaughan AS, Stevens GC. On radiation effects in poly(ethylene terephthalate): a comparison with poly(ether ether ketone). Polymer 1995;36(8):1541-7.

[27] Ungar G, Keller A. Radiation and the crystals of polyethylene and paraffins. In: Clough RL, Shalaby SW, editors. Radiation effects on polymers. ACS symposium series 475. Washington, DC: American Chemical Society; 1991. p. 101-18.

[28] Lucas P, Baba M, Lacoste J, Gardette JL. Crosslinking of dienic elastomers resulting from ageing: X-ray diffraction and refracto- metry measurements. Polym. Degrad. Stab. 2002;76(3):449-53.
[29] Olejniczak J, Rosiak J, Charlesby A. Gel/dose curves for polymers undergoing simultaneous crosslinking and scission. Radiat. Phys. Chem. 1991;37(3):499-504.

[30] Nandan B, Kandpal LD, Mathur GN. Poly(ether ether ketone)/ poly(aryl ether sulfone) blends: melt rheological behavior. J. Polym. Sci. B: Polym. Phys. 2004;42(8):1548-63.

[31] Sasuga T, Kudoh H, Seguchi T. High energy ion irradiation effects on polymer materials-changes in mechanical properties of PE, PSF and PES. Polymer 1999;40(18):5095-102.

[32] Audouin L, Langlois V, Verdu J, de Bruijn JCM. Role of oxygen diffusion in polymer ageing: kinetic and mechanical aspects. J. Mater. Sci. 1994;29(3):569-83.

[33] Emanuel NM, Buchachenko AL. Chemical physics of polymer degradation and stabilization (new concepts in polymer science). Utrecht: VNU Science press; 1990 [chapter 4].

[34] Heiland K, Hill DJT, Hopewell JL, Lewis DA, O'Donnell JH, Pomery PJ, et al. Measurement of radical yields to assess radiation resistance in engineering thermoplastics. Adv. Chem. Ser. 1996;249:637-50.

[35] Khelidj N, Colin X, Audouin L, Verdu J, Monchy-Leroy C, Prunier V. Oxidation of polyethylene under irradiation at low temperature and low dose rate. Part I. The case of "pure" radiochemical initiation. Polym. Degrad. Stab. 2006;91(7):1593-7.

[36] Alexander A, Charlesby A. Energy Transfer in Macromolecules Exposed to Ionizing Radiations. Nature 1954;173(4404):578-9.

[37] Kellman K, Hill DTJ, O’Donnell JH, Pomery PJ. Radiolysis of styrene. Methyl acrylate copolymers - an ESR study. Am. Chem. Soc., Polym. Prepr., Div. Polym. Chem. 1990;31(2):391-2.

[38] Thominette F, Metzger G, Dalle B, Verdu J. Radiochemical ageing of poly(vinyl chloride) plasticized by didecylphthalate. Eur. Polym. J. $1991 ; 27(1): 55-9$.

[39] Ismail MN, Ibrahim MS, Abd El-Ghaffar MA. Polyaniline as an antioxidant and antirad in SBR vulcanizate. Polym. Degrad. Stab. 1998;62(2):337-41.

[40] Gugumus F. Light stabilizers. In: Zweifel H, editor. Plastic additives handbook. Munich: Hanser; 2000. p. 141-424.

[41] Wise J, Gillen KT, Clough RL. Time development of diffusion-limited oxidation profiles in a radiation environment. Radiat. Phys. Chem. 1997;49(5):565-73.

[42] Wise J, Gillen KT, Clough RL. Quantitative model for the time development of diffusion-limited oxidation profiles. Polymer 1997;38(8):1929-44

[43] Gillen KT, Wise J, Clough RL. General solution for the basic autoxidation scheme. Polym. Degrad. Stab. 1995;47(1):149-61.

[44] Khelidj N, Colin X, Audouin L, Verdu J, Monchy-Leroy C, Prunier V. Oxidation of polyethylene under irradiation at low temperature and low dose rate. Part II. Low temperature thermal oxidation. Polym. Degrad. Stab. 2006;91(7):1598-605.

[45] Richaud E, Colin X, Fayolle B, Audouin L, Verdu J. Induction period in the low-temperature thermal oxidation of saturated hydrocarbons: example of polyethylene. Int. J. Chem. Kinet. 2008;40(12): 769-77.

[46] Van Krevelen DW. Properties of polymers. 3rd ed. New York: Elsevier; 1976 [chapter 18]

[47] Richaud E, Farcas F, Bartoloméo P, Fayolle B, Audouin L, Verdu J. Effect of oxygen pressure on the oxidation kinetics of unstabilised polypropylene. Polym. Degrad. Stab. 2006;91(2):398-405.

[48] Carlsson DJ, Brousseau R, Wiles DM. Reactions of sulfur dioxide with oxidized polyolefins. Polym. Degrad. Stab. 1986;15:67-79.

[49] Richaud E, Farcas F, Fayolle B, Audouin L, Verdu J. Accelerated ageing of polypropylene stabilized by phenolic antioxidants under high oxygen pressure. J. Appl. Polym. Sci. 2006;110(6):3313-21.

[50] Korcek S, Chenier JHB, Howard JA, Ingold KU. Absolute rate constants for hydrocarbon auto-oxidation - Activation energies for propagation ad the correlation of propagation rate constants. Can. J. Chem. 1972;50(14):2285-97.

[51] Molnár G, Botvay A, Pöppl L, Torkos K, Borossay J, Máthé Á, et al. Thermal degradation of chemically modified polysulfones. Polym. Degrad. Stab. 2005;89(3):410-7.

[52] Sasuga T, Hagiwara M. Radiation deterioration of several aromatic polymers under oxidative conditions. Polymer 1987;28(11): 1915-21.

[53] Colin X, Monchy-Leroy C, Audouin L, Verdu J. Lifetime prediction of polyethylene in nuclear plants. Nucl. Instrum. Methods Phys. Res. B 2007;265(1):251-5.

[54] Simha R, Boyer RF. On a general relation involving the glass temperature and coefficients of expansion of polymers. J. Chemi. Phys. 1962;37(5):1003-7.

[55] Bicerano J. Prediction of polymer properties. 3rd ed. New York: Marcel Dekker; 2002 [chapter 6]. 